\title{
Community water fluoridation, bone mineral density, and fractures: prospective study of effects in older women
}

Kathy R Phipps, Eric S Orwoll, Jill D Mason, Jane A Cauley

\begin{abstract}
Editorial by Hausen
School of Dentistry, Oregon Health

Sciences University,

611 SW Campus

Drive, Portland, OR

97201, USA

Kathy R Phipps

associate professor

Jill D Mason

associate professor

School of Medicine,

Oregon Health

Sciences University,

3181 SW Sam

Jackson Park Road,

Portland

Eric S Orwoll

professor of medicine

Department of

Epidemiology,

School of Public

Health, University

of Pittsburgh, 130

DeSoto Street,

Crabtree A524,

Pittsburgh, PA

15261, USA

Jane A Cauley

associate professor of

epidemiology

Correspondence to: K R Phipps

phippsk@ohsu.edu
\end{abstract}

BMJ 2000;321:860-4

\begin{abstract}
Objective To determine whether fluoridation influences bone mineral density and fractures in older women.

Design Multicentre prospective study on risk factors for osteoporosis and fractures.

Setting Four community based centres in the United States.

Participants 9704 ambulatory women without bilateral hip replacements enrolled during 1986-8; 7129 provided information on exposure to fluoride. Main outcome measures Bone mineral density of the lumbar spine, proximal femur, radius, and calcaneus plus incident fractures (fractures that occurred during the study) of vertebrae, hip, wrist, and humerus. Results Women were classified as exposed or not exposed or having unknown exposure to fluoride for each year from 1950 to 1994. Outcomes were compared in women with continuous exposure to fluoridated water for the past 20 years $(n=3218)$ and women with no exposure during the past 20 years $(\mathrm{n}=2563)$. In women with continuous exposure mean bone mineral density was $2.6 \%$ higher at the femoral neck $\left(0.017 \mathrm{~g} / \mathrm{cm}^{2}, \mathrm{P}<0.001\right), 2.5 \%$ higher at the lumbar spine $\left(0.022 \mathrm{~g} / \mathrm{cm}^{2}, \mathrm{P}<0.001\right)$, and $1.9 \%$ lower at the distal radius $\left(0.007 \mathrm{~g} / \mathrm{cm}^{2}, \mathrm{P}=0.002\right)$. In women with continuous exposure the multivariable adjusted risk of hip fracture was slightly reduced (risk ratio $0.69,95 \%$ confidence interval 0.50 to $0.96, \mathrm{P}=0.028$ ) as was the risk of vertebral fracture $(0.73,0.55$ to 0.97 , $\mathrm{P}=0.033)$. There was a non-significant trend toward an increased risk of wrist fracture (1.32, 1.00 to 1.71 , $\mathrm{P}=0.051)$ and no difference in risk of humerus fracture $(0.85,0.58$ to $1.23, \mathrm{P}=0.378)$.

Conclusions Long term exposure to fluoridated
\end{abstract} drinking water does not increase the risk of fracture.

\section{Introduction}

In 1945 Grand Rapids, Michigan, increased the fluoride concentration of its water supply to $1.0 \mathrm{ppm}$ and became the first city to implement water fluoridation. After 15 years children in Grand Rapids had a $56 \%$ reduction in rates of dental decay. ${ }^{1}$ Since 1950 the number of individuals drinking fluoridated water has steadily increased. Today an estimated 300 million people are exposed to fluoridated water, including 5.5 million in the United Kingdom and 144 million in the United States. ${ }^{2}$

While the benefit of fluoridation in the prevention of dental caries has been overwhelmingly substantiated, the effect of fluoridation on bone mineral density and rates of fracture is inconsistent. Ecological studies that compare rates of fracture specific for age and sex between fluoridated and non-fluoridated communities have variously found that exposure to fluoridated water increases the risk of hip fracture, ${ }^{3-5}$ increases the risk of proximal humerus and distal forearm fracture, ${ }^{6}$ has no effect on fracture risk, ${ }^{7-10}$ and decreases the risk of hip fracture. ${ }^{112}$ Ecological studies, however, have a major design flaw-they are based on community level data and cannot control for confounding variables at the individual level.

We determined, on an individual level, whether older women with long term exposure to fluoridated water had different bone mass and rates of fracture compared with women with no exposure. Given our widespread exposure to fluoridation, the impact of fluoride on rates of fracture is an important public health issue. In a previous study in which we found no effect of fluoridation on bone mass or risk of fracture in women we had limited power to look at individual fractures and had a relatively small proportion of women exposed to fluoride for long duration. ${ }^{13}$ In the current study we increased power to look at individual fractures by increasing the number of participants, including more women with long term exposure to fluoride, and following the population for a longer period of time

\section{Methods}

Participants-This study was ancillary to the study of osteoporotic fractures, a multicentre study of risk factors for osteoporosis and fractures. During 1986-8 we recruited 9704 white women aged at least 65 years in Portland, Oregon; Minneapolis, Minnesota; Baltimore, Maryland; and the Monongahela Valley (an area with several small communities) in Pennsylvania. Recruitment sources included lists for jury selection and registration of voters, motor vehicle records, and membership records of health plans. Men and black women were excluded as were white women who were unable to walk without assistance and women who had a bilateral hip replacement.

Exposure to fluoridated water-Exposure to fluoridated water was assessed with a questionnaire on residence history. Women were asked to list each address (street, city, state, and postal code), years they lived at that address, and the type of water supply (public, well, spring, etc) for each of their residences from 1950 to 1994. Water system maps and the 1992 fluoridation census $^{2}$ were used to link street addresses with water system and fluoridation status. If a question arose, the appropriate water district was contacted to ascertain water source and fluoride content. For each year women were coded as being exposed or not exposed or having unknown exposure. The coding of unknown was used for residences outside the United States, incomplete addresses, and private wells in areas with naturally occurring fluoride. The questionnaire was sent to the 7612 women still active in the study and $94 \%$ (7129) completed it. To assess the reliability of the residence history, duplicate histories were completed by a randomly selected group of 103 women. The $\kappa$ 
statistic for agreement between fluoride exposure was 0.94 .

Measurement of bone mass-Bone mineral density $\left(\mathrm{g} / \mathrm{cm}^{2}\right)$ of the distal radius, proximal radius, and calcaneus were measured with single photon absorptiometry (Osteo-Analyzer, Siemens-Osteon, Wahiawa, Hawaii). Bone mineral density of the lumbar spine and proximal femur were measured with dual energy $x$ ray absorptiometry (QDR 1000, Hologic Inc, Waltham, Massachusetts).

Assessment of risk factors-Information on medical history, drugs and supplements, reproductive history, menopause, alcohol consumption, exercise, smoking, caffeine intake, and history of fractures was obtained through a questionnaire. Dietary calcium was assessed by a food frequency questionnaire administered by an interviewer. ${ }^{14}$ Women were also asked about walking, time spent sitting or lying down, and the amount of difficulty experienced with activities of daily living. Height and weight were also measured. ${ }^{15}$

Ascertainment of incident non-spinal fractures-During the study participants were contacted every four months to inquire if a fracture had occurred (incident fracture). About $99 \%$ of these contacts were completed. ${ }^{16}$ If a fracture was reported the woman was interviewed and a copy of the radiographic report obtained. To be coded as a fracture the report had to mention the occurrence of an acute fracture. Fractures due to major trauma were excluded. All fractures that occurred up until 1 December 1995 were included (average follow up of 7.0 years).

Ascertainment of prevalent and incident vertebral fractures-Lateral radiographs of the thoracic and lumbar spine were taken during the first clinical visit. A vertebral body was considered to have a prevalent fracture (fracture that had occurred before the study) if any of the following ratios were more than $3 \mathrm{SD}$ below the mean: the ratio of anterior to posterior height, mid-height to posterior height, and anterior height to the anterior height of the adjacent vertebrae. ${ }^{17}$ Repeat radiographs were obtained from 7238 women (average follow up of 4.0 years). The following definition of an incident vertebral fracture was used: a 20\% reduction in the vertebral height of the anterior, middle, or posterior dimension of a vertebral body and at least a $4 \mathrm{~mm}$ decrease in the vertebral height of a dimension.

Statistical analysis-To evaluate the effect of long term fluoride exposure we statified data by fluoride exposure. Women with no exposure during 1971-90 $(n=2563)$ were compared with women with continuous exposure $(\mathrm{n}=3218)$ and women with mixed expo-
Table 1 Characteristics of women by exposure to fluoride in drinking water, 1971-1990. Figures are proportion of women unless stated otherwise

\begin{tabular}{lccc} 
Category & $\begin{array}{c}\text { No exposure } \\
(\mathbf{n}=\mathbf{2 5 6 3 )}\end{array}$ & $\begin{array}{c}\text { Mixed exposure } \\
(\mathbf{n}=\mathbf{1 3 4 8})\end{array}$ & $\begin{array}{c}\text { Continuous exposure } \\
(\mathbf{n}=\mathbf{3 2 1 8})\end{array}$ \\
\hline Mean age (years) & 74.5 & 74.2 & $73.9^{*}$ \\
\hline Education $>12$ years & 33.0 & 32.6 & $45.1^{*}$ \\
\hline Mean weight $(\mathrm{kg})$ & 68.5 & 67.7 & $66.5^{*}$ \\
\hline Walks for exercise & 52.6 & 50.6 & 52.1 \\
\hline Mean muscle strength (knee extension) $(\mathrm{kg})$ & 19.4 & $17.9^{*}$ & $17.0^{*}$ \\
\hline Mean muscle strength (grip strength) $(\mathrm{kg})$ & 21.0 & 20.7 & $21.5^{*}$ \\
\hline Fall in past 12 months & 29.5 & 28.9 & 28.9 \\
\hline Surgical menopause & 15.2 & $11.5^{*}$ & $11.5^{*}$ \\
\hline Mean calcium intake (mg/week) & 4733 & 4735 & $5189^{*}$ \\
\hline No difficulties in functional status & 79.8 & 79.9 & 80.1 \\
\hline Mean No of alcohol drinks/week & 1.4 & 1.5 & $2.4^{*}$ \\
\hline Current smoker & 8.5 & 9.8 & 9.5 \\
\hline History of medical conditions: & & & $14.4 \dagger$ \\
\hline Osteoporosis & 12.2 & $14.4 \dagger$ & $4.1^{*}$ \\
\hline Non-insulin dependent diabetes & 6.5 & 6.9 & 20.4 \\
\hline Current oestrogen use & 18.8 & $15.4 \dagger$ & $24.8^{*}$ \\
\hline Current thiazide diuretic use & 29.0 & 26.7 & $10.7 \dagger$ \\
\hline Current thyroid hormone use & 12.8 & 13.3 &
\end{tabular}

${ }^{*} P \leqslant 0.001$ compared with category of no exposure.

$\dagger P \leqslant 0.050$ compared with category of no exposure.

sure $(n=1348)$. A 20 year period was selected because information on residence history for dates before 1971 was less reliable. We used $\chi^{2}$ tests of homogeneity and analysis of variance and covariance to compare mean bone mineral density and other covariates across the exposure groups. We used proportional hazard and logistic regression models to assess the relation between fluoride and incident fractures. Multivariable models included those factors that differed between the fluoride exposure groups plus factors previously shown to be significantly related to skeletal health in the study of osteoporotic fractures. ${ }^{19} 19$

\section{Results}

Characteristics of the study population-Compared with women with continuous exposure, women with no exposure were older and heavier, were more likely to have had a surgical menopause, reported a higher use of both thiazide diuretics and thyroid hormones, drank less alcohol, had lower calcium intakes, had higher muscle strength at the knee but lower grip strength, and were less likely to have more than a high school education (table 1). There was no difference in physical activity, history of falls, functional status, or smoking. Women with no or mixed exposure were more likely to have non-insulin dependent diabetes

Table 2 Age adjusted bone mineral density $\left(\mathrm{g} / \mathrm{cm}^{2}\right)$ with $95 \%$ confidence intervals by exposure to fluoride in drinking water, 1971-90

\begin{tabular}{|c|c|c|c|c|c|}
\hline \multirow[b]{2}{*}{ Anatomical site } & \multirow[b]{2}{*}{ No exposure } & \multirow[b]{2}{*}{ Mixed exposure } & \multirow[b]{2}{*}{ Continuous exposure } & \multicolumn{2}{|c|}{$P$ value } \\
\hline & & & & $\begin{array}{c}\text { No exposure } v \\
\text { mixed }\end{array}$ & $\begin{array}{c}\text { No exposure } v \\
\text { continuous }\end{array}$ \\
\hline Lumbar spine $(n=6433)$ & 0.857 (0.850 to 0.864$)$ & $0.850(0.840$ to 0.860$)$ & 0.866 (0.860 to 0.873$)$ & 0.262 & 0.045 \\
\hline \multicolumn{6}{|l|}{ Proximal femur $(n=6420)$ : } \\
\hline Neck & 0.651 (0.647 to 0.658$)$ & 0.650 (0.645 to 0.657$)$ & 0.661 (0.657 to 0.664$)$ & 0.871 & 0.002 \\
\hline Trochanter & $0.562(0.558$ to 0.566$)$ & 0.559 (0.553 to 0.564$)$ & 0.568 (0.565 to 0.572$)$ & 0.355 & 0.032 \\
\hline Ward's triangle & $0.432(0.428$ to 0.437$)$ & 0.431 (0.426 to 0.438$)$ & 0.437 (0.433 to 0.441$)$ & 0.915 & 0.104 \\
\hline Intertrochanter & 0.901 (0.895 to 0.908$)$ & 0.887 (0.879 to 0.896$)$ & 0.888 (0.882 to 0.894$)$ & 0.014 & 0.002 \\
\hline Distal radius $(\mathrm{n}=7067)$ & 0.371 (0.367 to 0.374$)$ & $0.358(0.354$ to 0.363$)$ & 0.364 (0.361 to 0.367$)$ & $<0.001$ & 0.001 \\
\hline Proximal radius $(n=7113)$ & 0.647 (0.643 to 0.651$)$ & 0.631 (0.626 to 0.637$)$ & 0.636 (0.632 to 0.639$)$ & $<0.001$ & $<0.001$ \\
\hline Calcaneus $(n=7104)$ & 0.413 (0.409 to 0.416$)$ & 0.401 (0.396 to 0.405$)$ & 0.409 (0.406 to 0.412$)$ & $<0.001$ & 0.105 \\
\hline
\end{tabular}


Table 3 Multivariate adjusted* bone mineral density $\left(\mathrm{g} / \mathrm{cm}^{2}\right)$ with $95 \%$ confidence intervals by exposure to fluoride in drinking water, $1971-90$

\begin{tabular}{|c|c|c|c|c|c|c|}
\hline \multirow[b]{2}{*}{ Anatomical site } & \multirow[b]{2}{*}{ No exposure } & \multirow[b]{2}{*}{ Mixed exposure } & \multirow[b]{2}{*}{ Continuous exposure } & \multirow{2}{*}{$\begin{array}{l}\text { No exposure } v \\
\text { continuous } \\
\text { (\% difference) }\end{array}$} & \multicolumn{2}{|c|}{$P$ value } \\
\hline & & & & & $\begin{array}{c}\text { No exposure } \\
v \text { mixed }\end{array}$ & $\begin{array}{l}\text { No exposure } \\
v \text { continuous }\end{array}$ \\
\hline Lumbar spine ( $\mathrm{n}=6433$ ) & 0.849 (0.843 to 0.856$)$ & 0.853 (0.844 to 0.862$)$ & 0.871 (0.865 to 0.877$)$ & 2.5 & 0.440 & $<0.001$ \\
\hline \multicolumn{7}{|l|}{ Proximal femur $(\mathrm{n}=6420)$ : } \\
\hline Neck & $0.647(0.643$ to 0.651$)$ & $0.652(0.646$ to 0.657$)$ & 0.664 (0.661 to 0.668$)$ & 2.6 & 0.122 & $<0.001$ \\
\hline Trochanter & 0.558 (0.554 to 0.562$)$ & 0.561 (0.555 to 0.566$)$ & $0.572(0.568$ to 0.575$)$ & 2.4 & 0.314 & $<0.001$ \\
\hline Ward's triangle & $0.429(0.424$ to 0.434$)$ & 0.433 (0.428 to 0.439$)$ & $0.439(0.436$ to 0.443$)$ & 2.3 & 0.260 & 0.002 \\
\hline Intertrochanter & 0.892 (0.887 to 0.898$)$ & 0.889 (0.882 to 0.897$)$ & 0.895 (0.889 to 0.900$)$ & 0.3 & 0.652 & 0.737 \\
\hline Distal radius $(\mathrm{n}=7067)$ & 0.371 (0.367 to 0.374$)$ & $0.362(0.357$ to 0.366$)$ & $0.364(0.361$ to 0.367$)$ & -1.9 & 0.003 & 0.002 \\
\hline Proximal radius $(n=7113)$ & 0.645 (0.642 to 0.649$)$ & 0.637 (0.632 to 0.642$)$ & 0.636 (0.633 to 0.639$)$ & -1.4 & 0.010 & $<0.001$ \\
\hline Calcaneus $(n=7104)$ & 0.408 (0.405 to 0.412$)$ & 0.402 (0.398 to 0.407 ) & $0.413(0.410$ to 0.416$)$ & 1.2 & 0.134 & 0.410 \\
\hline
\end{tabular}

${ }^{*}$ Adjusted for age, weight, education, knee/grip strength, surgical menopause, calcium intake, drinks/week, current oestrogen use, current thiazide use, non-insulin dependent diabetes, current thyroid hormone use, walking for exercise, and smoking status.

Table 4 Proportion of women with incident fracture stratified by exposure to fluoride in drinking water and site of fracture (unadjusted), 1971-90

\begin{tabular}{lccc} 
Fracture site & No exposure & Mixed exposure & $\begin{array}{c}\text { Continuous } \\
\text { exposure }\end{array}$ \\
\hline Non-vertebral & 22.3 & 24.3 & 22.6 \\
\hline Spine & 5.6 & 4.3 & 4.4 \\
\hline Hip & 3.6 & 3.4 & 2.9 \\
\hline Humerus & 2.8 & 3.0 & 2.4 \\
\hline Wrist & 4.4 & 4.8 & 5.8
\end{tabular}

and women with mixed exposure reported a lower use of oestrogen.

Bone mineral density-Tables 2 and 3 give data on bone mineral density adjusted for age and other variables for the lumbar spine, proximal femur, radius, and calcaneus stratified by fluoride exposure. Compared with women with no exposure, women with continuous exposure had significantly higher bone mineral density of the lumbar spine, femoral neck, and trochanter, but significantly lower density of the radius. Women with mixed exposure tended to have bone density values between the other exposure groups.

Table 5 Risk of incident fracture in women according to exposure to fluoride in drinking water

\begin{tabular}{llllll} 
& \multicolumn{2}{c}{ Age adjusted $^{*}$} & & \multicolumn{2}{c}{ Multivariable adjusted $^{*} \dagger$} \\
\cline { 2 - 3 } & Relative risk (95\% CI) & P value & & Relative risk (95\% CI) & P value \\
\hline All non-vertebral fractures & & & & \\
\hline Mixed exposure & $1.12(0.96$ to 1.32$)$ & 0.147 & & $1.03(0.87$ to 1.22$)$ & 0.733 \\
\hline Continuous exposure & $1.04(0.92$ to 1.19$)$ & 0.410 & & $0.96(0.83$ to 1.10$)$ & 0.536 \\
\hline Spine & & & & \\
\hline Mixed exposure & $0.78(0.55$ to 1.10$)$ & 0.152 & $0.73(0.50$ to 1.06$)$ & 0.096 \\
\hline Continuous exposure & $0.79(0.61$ to 1.03$)$ & 0.079 & $0.73(0.55$ to 0.97$)$ & 0.033 \\
\hline Hip & & & & \\
\hline Mixed exposure & $0.97(0.67$ to 1.39$)$ & 0.858 & $0.73(0.49$ to 1.09$)$ & 0.126 \\
\hline Continuous exposure & $0.85(0.63$ to 1.14$)$ & 0.287 & $0.69(0.50$ to 0.96$)$ & 0.028 \\
\hline Humerus & & & & \\
\hline Mixed exposure & $1.09(0.73$ to 1.61$)$ & 0.677 & $1.03(0.67$ to 1.57$)$ & 0.906 \\
\hline Continuous exposure & $0.89(0.64$ to 1.24$)$ & 0.491 & $0.85(0.58$ to 1.23$)$ & 0.378 \\
\hline Wrist & & & & \\
\hline Mixed exposure & $1.11(1.52$ to 0.81$)$ & 0.514 & $1.09(0.78$ to 1.52$)$ & 0.628 \\
\hline Continuous exposure & $1.36(1.07$ to 1.73$)$ & 0.012 & $1.32(1.00$ to 1.71$)$ & 0.051
\end{tabular}

*Reference group: women with no exposure.

†Adjusted for age, weight, education, muscle strength, surgical menopause, calcium intake, drinks/week, current oestrogen use, current thiazide use, non-insulin dependent diabetes, current thyroid hormone use, walking for exercise, and smoking status.
Incident fractures-Twenty three per cent of the women experienced at least one non-vertebral fracture during observation. Women with continuous exposure had fewer fractures of the spine, hip, and humerus but more wrist fractures than women with no exposure (table 4). After adjustment for potential confounders, women with continuous exposure had a $31 \%$ reduction in risk of hip fracture $(\mathrm{P}=0.028)$ and a $27 \%$ reduction in risk of vertebral fracture $(\mathrm{P}=0.033)$. There was a trend towards fewer fractures of the humerus $(\mathrm{P}=0.387)$ and more fractures of the wrist $(\mathrm{P}=0.051)$, but the differences were not significant. The risk of fracture in women with mixed exposure did not differ from that in women with no exposure (table 5).

\section{Discussion}

Osteoporosis is a major public health problem. In the European Community osteoporosis is responsible for more than one million fractures each year, and the number is expected to increase. Because of this it is imperative that steps be taken to understand the determinants of fracture and to decrease the population's risk of osteoporosis and subsequent fractures.

\section{Strength of study}

In the 1950 s and 1960s several cross sectional studies suggested an increase in bone density in individuals living in fluoridated areas. ${ }^{20-22}$ These early studies, however, failed to control for important confounding variables. To overcome this problem, we considered known confounders. In addition, we included only those fractures confirmed by radiographic report and carefully assessed long term exposure to fluoridated water. Using a prospective design, mixed with a retrospective assessment of fluoride exposure, we found that exposure to fluoridation was associated with an increase in bone mass at the lumbar spine and proximal femur and a slight decrease in the risk of hip and vertebral fractures. We also found that women with long term exposure to fluoridated water had decreased bone mineral density of the radius. Women with mixed exposure tended to have fracture risks between those seen in women with no exposure and those with continuous exposure, especially at the hip and wrist. 


\section{What is already known on this topic}

Several ecological studies have found that rates of hip fracture are higher in communities with fluoridated drinking water compared with communities without fluoridation

These studies, however, have not controlled for several factors known to be associated with rates of fracture including use of oestrogen, smoking, and body weight

\section{What this study adds}

Long term exposure to fluoridation does not increase the risk of osteoporotic fracture among older women

In terms of any effect on bone mineral density community water fluoridation as a public health measure for the prevention of dental caries is safe

\section{Comparisons with recent research}

In addition to the definitive concordance we found between bone mineral density and fractures, our findings are consistent with results of recent studies that evaluated the impact of fluoridation on bone mineral density and fractures. In a study of 3222 women Kroger et al found higher bone mineral density of the lumbar spine (2.7\%) and femoral neck (1.1\%) among postmenopausal women exposed to fluoridation for at least 10 years. ${ }^{23}$ Hillier et al, however, found no association between fluoridation and risk of hip fracture risk in a case-control study of men and women aged 50 years and older (odds ratio 1.0, 95\% confidence interval 0.7 to 1.5$).^{24}$

Adults living in non-fluoridated areas have an estimated fluoride intake of $0.88-2.20 \mathrm{mg}$ /day compared with $1.58-6.60 \mathrm{mg}$ for adults in a fluoridated area. ${ }^{25}$ The plasma fluoride concentrations of people in fluoridated areas are usually between 0.7-2.4 $\mu \mathrm{mol} / 1 .{ }^{26}$ Although low, these concentrations have been shown to affect the mitogenic activity of bone cells in vitro. Farley et al report that fluoride, in concentrations as low as $1 \mu \mathrm{mol} / \mathrm{l}$, increases bone cell proliferation. ${ }^{27}$ It is reasonable to expect that concentrations of fluoride at 1 ppm may have discernible skeletal effects after 20 years of exposure.

\section{Fluoride biomarker}

Fluoride is ubiquitous and is found in food, water, air, and dental products. It is estimated, however, that about $80 \%$ of dietary fluoride is from water and beverages. $^{28}{ }^{29}$ Detailed histories of residence are the best tool currently available to estimate long term fluoride exposure. Because concentrations of environmental fluoride are low, the distinction between the exposed and the unexposed population is often blurred, making the traditional tool of epidemiology (questionnaires) less sensitive. ${ }^{30} \mathrm{~A}$ biomarker of exposure could increase sensitivity in studies on the impact of fluoride on osteoporosis. The only validated biomarker for long term fluoride exposure is fluoride concentrations in bone. While bone biopsies provide an accurate concentration of total body burden of fluoride they are unacceptable to patients. Fluoride concentrations in fasting plasma, saliva, and nails may be potential measures of exposure. The development and validation of a fluoride biomarker is an essential next step in the continued study of the relation between fluoride and skeletal health.

\section{Conclusion}

This is the first prospective study with adequate power to examine the risk of specific fractures associated with fluoride on an individual rather than a community basis. Our results show that long term exposure to fluoridation may reduce the risk of fractures of the hip and vertebrae in older white women. Because the burden of osteoporosis is largely due to fractures of the hip, this finding may have enormous importance for public health. If fluoridation does reduce the risk of hip fracture it may be one of the most cost effective methods for reducing the incidence of fractures related to osteoporosis. In addition, our results support the safety of fluoridation as a public health measure for the control of dental caries.

Contributors: KRP (guarantor) developed the study protocols, coordinated the study, and participated in data analysis, interpretation, and writing of the paper. ESO participated in the protocol design, interpretation of the data, and writing of the paper. JDM participated in the design and execution of the study including data collection, data documentation, quality control, and writing of the paper. JAC had the original idea for the present study and participated in data collection, interpretation of the data, and writing of the paper.

Funding: United States National Institutes of Health (DE10814, AG05407, AR35582, AG05394, AR35584, AR35583). United States Environmental Protection Agency, Center for Environmental Epidemiology, University of Pittsburgh. The views expressed are those of the authors and do not necessarily reflect the views or policies of the US Environmental Protection Agency.

Competing interests: None declared.

1 Burt BA, Eklund SA. Dentistry, dental practice, and the community. 4th ed. Philadelphia: Saunders, 1992.

2 Public Health Service, CDC, Division of Oral Health. Fluoridation Census 1992. Atlanta, GA: US Department of Health and Human Services, 1993 3 Jacobsen SJ, Goldberg J, Cooper C, Lockwood SA. The association between water fluoridation and hip fracture among white women and men aged 65 years and older. A national ecologic study. Ann Epidemiol 1992;2:617-26.

4 Danielson C, Lyon JL, Egger M, Goodenough GK. Hip fractures and fluoridation in Utah's elderly population. JAMA 1992;268:746-8.

5 Jacobsen SJ, Goldberg J, Miles TP, Brody JA, Stiers W, Rimm AA. Regional variation in the incidence of hip fracture. US white women aged 65 years and older. JAMA 1990;264:500-2.

6 Karagas MR, Baron JA, Barrett JA, Jacobsen SJ. Patterns of fracture among the United States elderly: geographic and fluoride effects. Ann Epidemiol 1996;6:209-16.

7 Madans J, Kleinman JC, Cornoni-Huntley J. The relationship between hip fracture and water fluoridation: an analysis of national data. Am J Public Health 1983:73:296-8.

8 Avorn J, Niessen LC. Relationship between long bone fractures and water fluoridation. Gerodontics 1986;2:175-9.

9 Arnala I, Alhava EM, Kivivuori R, Kauranen P. Hip fracture incidence not affected by fluoridation. Osteofluorosis studied in Finland. Acta Orthop Scand 1986;57:344-8.

10 Cooper C, Wickham C, Lacey RF, Barker DJ. Water fluoride concentration and fracture of the proximal femur.J Epidemiol Community Health 1990;44:17-9.

11 Simonen O, Laitinen O. Does fluoridation of drinking-water prevent bone fragility and osteoporosis? Lancet 1985;ii:432-4.

12 Jacobsen SJ, O'Fallon WM, Melton LJ. Hip fracture incidence before and after fluoridation of the public water supply, Rochester, Minnesota. Am Public Health 1993;83:743-5.

13 Cauley JA, Murphy PA, Riley TJ, Buhari AM. Effects of fluoridated drinking water on bone mass and fractures: the study of osteoporotic fractures. J Bone Miner Res 1995;10:1076-86.

14 Cummings SR, Block G, McHenry K, Baron RB. Evaluation of two food frequency methods of measuring dietary calcium intake. Am J Epidemiol 1987;126:796-802.

15 Kelsey JL, Browner WS, Seeley DG, Nevitt MC, Cummings SR. Risk factors for fractures of the distal forearm and proximal humerus. The study of osteoporotic fractures research group. Am J Epidemiol 1992;135: $477-89$. 
16 Cummings SR, Nevitt MC, Browner WS, Stone K, Fox KM, Ensrud KE, et al. Risk factors for hip fracture in white women. The study of osteoporotic fractures research group. $N$ Engl J Med 1995;332:767-73.

17 Black DM, Palermo L, Nevitt MC, Genant HK, Epstein R, San Valentin $\mathrm{R}$, et al. Comparison of methods for defining prevalent vertebral fractures: the study of osteoporotic fractures. J Bone Miner Res 1995;10: 890-902.

18 Bauer DC, Browner WS, Cauley JA, Orwoll ES, Scott JC, Black DM, et al. Factors associated with appendicular bone mass in older women. The study of osteoporotic fractures research group. Ann Intern Med 1993;118:657-65.

19 Orwoll ES, Bauer DC, Vogt TM, Fox KM. Axial bone mass in older women. Study of osteoporotic fractures research group. Ann Intern Med $1996 ; 124: 187-96$

20 Leone NC, Stevenson CA, Hilbish TF, Sosman MC. A roentgenologic study of human population exposed to high-fluoride domestic water (a 10-year study). In: McClure FJ, ed. Fluoride drinking waters. Bethesda, MD: National Institute of Dental Research, 1962 (DHEW Publ No (PHS)62-825).

21 Bernstein DS, Sadowsky N, Hegsted DM, Guri D, Stare FJ. Prevalence of osteoporosis in high- and low-fluoride areas in North Dakota. JAMA 1966;198:499-504

22 Ansell BM, Lawrence JS. Fluoridation and the rheumatic diseases. A comparison of rheumatism in Watford and Leigh. Ann Rheum Dis $1966 ; 25: 67-75$.
23 Kroger H, Alhava E, Honkanen R, Tuppurainen M, Saarikoski S. The effect of fluoridated drinking water on axial bone mineral density-a population-based study. Bone Miner 1994;27:33-41.

24 Hillier S, Cooper C, Killingray S, Russell G, Hughes H, Coggon D. Fluoride in drinking water and risk of hip fracture in the UK: a case-control study. Lancet 2000;335:265-9.

25 Ad-Hoc Subcommittee on Fluoride. Review of fluoride benefits and risks. Bethesda, MD: Public Health Service, Department of Health and Human Services, 1991:17.

26 Whitford GM. The metabolism and toxicity of fluoride. Monogr Oral Sci 1996;16(2):1-153.

27 Farley JR, Tarbaux N, Hall S, Baylink DJ. Evidence that fluoride-stimulated 3[H]-thymidine incorporation in embryonic chick calvarial cell cultures is dependent on the presence of a bone cell mitogen, sensitive to changes is depend in the phosphate concentration, a

28 Dabeka RW, McKenzie AD. Survey of lead, cadmium, fluoride, nickel, and cobalt in food composites and estimation of dietary intakes of these elements by Canadians in 1986-1988. J AOAC Int 1995;78:897-909.

29 Lahti SM, Uusitalo U, Feskens E, Haw U, Tuomilehto J, Luoma H. Fluoride and sugar intake among adults and youth in Mauritius: preliminary results. Adv Dent Res 1995;9:21-5.

30 Silbergeld EK, Davis DL. Role of biomarkers in identifying and understanding environmentally induced disease. Clin Chem 1994;40:1363-7.

(Accepted 5 July 2000)

\title{
Audit of oxygen prescribing before and after the introduction of a prescription chart
}

\author{
M E Dodd, F Kellet, A Davis, J C G Simpson, A K Webb, C S Haworth, R McL Niven
}

North West Lung

Centre, South

Manchester

University Hospitals

Trust, Manchester

M23 9LT

M E Dodd

specialist

physiotherapy

clinician

F Kellet

senior physiotherapist

A Davis

senior physiotherapist

A K Webb

consultant physician

C S Haworth

research fellow

R McL Niven

consultant physician

Stepping Hill

Hospital, Poplar

Grove, Stockport

SK2 7JE

J C G Simpson

senior registrar

Correspondence to:

M E Dodd

doddmary@

hotmail.com

BMJ 2000;321:864-5
Oxygen, used to treat hypoxaemia, may be lethal and should therefore be considered a drug and be prescribed. ${ }^{1}$ It is, however, recognised that oxygen is poorly prescribed by doctors. ${ }^{2}$ To ensure the safe and effective delivery of oxygen the prescription should include the flow rate, the concentration, the delivery device, the duration, and the method for monitoring treatment. ${ }^{2}$ We audited the prescription of oxygen to inpatients by doctors before and after the introduction of a specific prescription chart.

\section{Participants, methods, and results}

Junior doctors at the North West Lung Centre are given two lectures on practical aspects of oxygen delivery and prescribing at the beginning of their one year's rotation in respiratory medicine. In 1997 and 1998 the doctors were informed that an audit of their prescribing practice would take place some time during the next year. The outcome measures of the audit were whether the oxygen was prescribed and whether the prescription was accurate-that is, that the audit matched patient use in relation to the delivery device and that the flow rate and concentration were appropriate to that device.

The audit was conducted on three respiratory wards over three months. FK and AD identified all patients receiving oxygen within 24 hours of admission, and they recorded the device, oxygen concentration, and flow rate appropriate to the device for each patient. They consulted a drug Kardex for a prescription of the proposed oxygen treatment. If a prescription was present they recorded the device, concentration, and flow rate. After the first audit, a specific prescription chart for oxygen was developed to encompass all the oxygen delivery systems used on the wards (figure). The methodology for the second audit was identical to that of the first, with the exception that both the chart and the drug Kardex were examined for the prescription. The $\chi^{2}$ test was used to analyse the prescription of oxygen before and after the introduction of the chart.

Overall, 115 patients were identified as receiving oxygen in the first audit and 121 in the second. In the first audit oxygen was prescribed for 63 of the 115 $(55 \%)$ patients. After the chart was introduced the number of oxygen treatments prescribed increased to 110 of $121(91 \%)$ patients $(\mathrm{P}<0.001)$. The prescription was accurate for eight $(7 \%)$ patients in the first audit and $93(77 \%)$ in the second. The accuracy of prescription was $94 \%$ (73 of 78 patients) with the chart and $63 \%$ (20 of 32) with the drug Kardex.

\section{Comment}

Our first audit showed that oxygen was infrequently well prescribed, as previously described. ${ }^{23}$ Junior doctors poorly understand the effects and dangers of oxygen, and lectures alone were insufficient to ensure safe and effective practice. ${ }^{4}$ The prescription chart for oxygen listed the delivery devices, guided the doctor to prescribe the appropriate concentration and flow rate, and provided additional notes for the specific indications of each device.

The most common omission from the prescriptions was flow rate. The flow rate of fixed concentration masks should be adjusted for patients with high peak inspiratory flows. Flow rate is the only variable that is prescribed with nasal cannulas, and an accurate prescription of flow rate is essential as hypercapnic respiratory failure may occur. ${ }^{4}$ Oxygen for delivery by nasal cannula is often prescribed by 